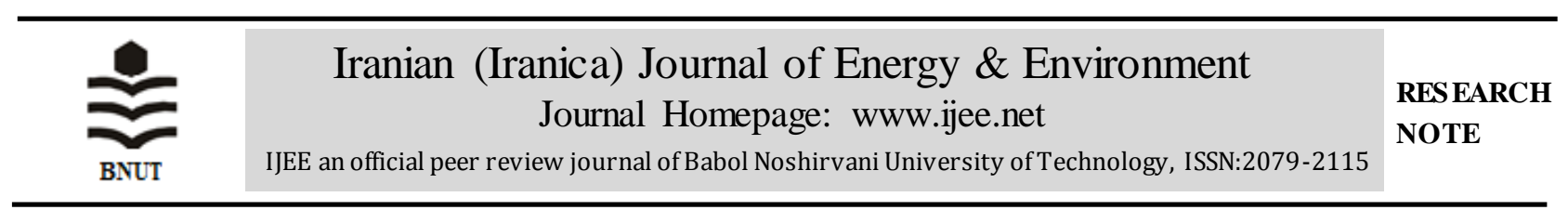

\title{
Passive Cooling in Shavadoon of Traditional Buildings of Dezful City: Cooling Through Renewable Energy Sources
}

\author{
F. Mohammad-Alinezhad*
}

Department of Architecture, Faculty of Engineering, Shahid Chamran University of Ahvaz, Ahvaz, Iran

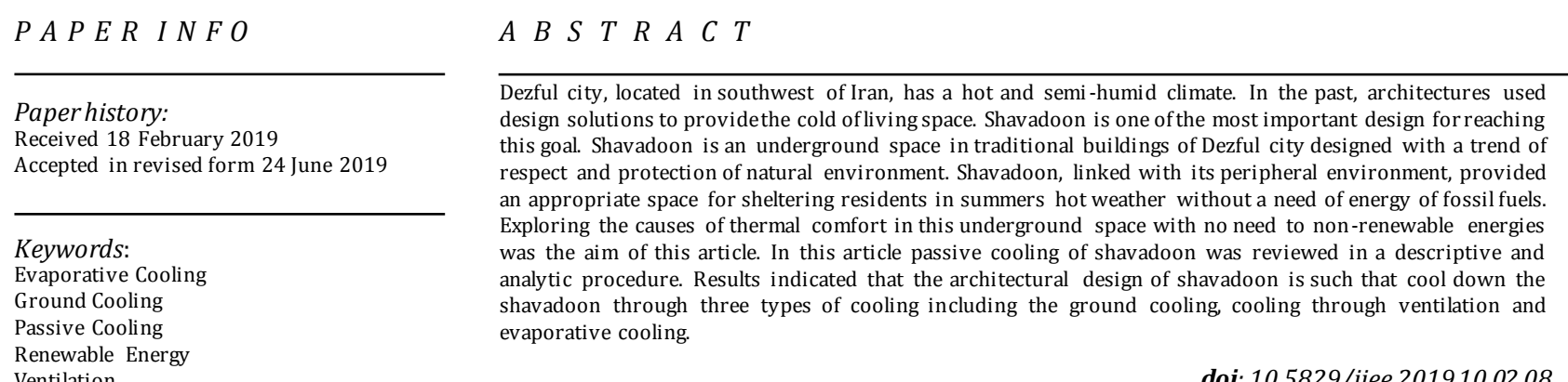

\section{INTRODUCTION}

Due to increased environmental pollution, using renewable energy in design and construction of an environmentally friendly buildings is in high importance. In traditional architecture of Iran, there is a thoughtful interaction with nature. Buildings that fit the climate and have no need for fossil fuels for cooling and heating are the manifestations of this interaction leading to the protecting of environment [1]. One of the spaces designed with such attitude is shavadoon of Dezful city.

Shavadoon is an underground space which is designed in accordance with climatic conditions of Dezful city to make it possible for its habitants to live in hot conditions during summer. Introducing of the architecture of the shavadoon, climatic analysis, thermal behavior and sustainability of shavadoon were considered in previous studies [1-9]. In some modeling researches, the difference between shavadoons in terms of their component has been considered [6,10]. The results of these researches prove the valuable features of shavadoon in meeting the needs of residents with respect for environment. Bina [1] studied on the internal temperature of shavadoon, reported that temperature of shavadoon was lower than the minimum outside temperature during summer warm days and was in the comfort range. He also concluded that there was a negligible difference between shavadoon temperature and comfort range, leading to no need for heating device and energy consumption. Masoudi et al. [9], evaluated the thermal behavior of the shavadoon in Souzangar house and concluded that there was a thermal comfort during different seasons and moisture was removed through the entrance door of shavadoon. Dehghan and Vakili-nejad [2] considered the influential factors in the formation of underground architecture, including the architecture of shavadoon and observed that passive cooling through earth mass was on the main factors in the formation of underground architecture. In addition, introduced the climate, security and soil type as effective factors in the formation of shavadoon. Hazbei, et al. [6] analyzed air flow in some shavadoons of Dezful city and determined the best combination between the components of shavadoon for natural ventilation. Mohammad-shahi et al. [10] investigated the improvement of ventilation and the transfer of heat in shavadoon and concluded that the geometric parameters of the components of the shavadoon are effective in improving its performance.

The aim of this article was the understanding of the performance of shavadoon, as an architectural space, in achieving passive cooling through considering the following questions: 1. what is shavadoon and its component? 2. What is passive cooling and how it is achieved in shavadoon? 3. How can the combination between shavadoon component lead to a passive cooling and thermal comfort?

\footnotetext{
Corresponding Author Email: fa.ma.nezhad@gmail.com (Fatemeh
} Mohammad-Alinezhad) 


\section{PASSIVE COOLING IN BUILDING}

Passive cooling is an important way in exploiting renewable energy resources in which energy flow in building is controlled through natural methods (guidance or relocation of radiation) to achieve thermal comfort without using any secondary energy. Passive cooling focuses on heat reducers [11].

According to Figure 1, there are three categories for the strategies of passive cooling for buildings [12]: heat prevention, heat modulation and heat dissipation.

\section{Heat prevention}

This strategy has a close relationship with solar radiation in which external heat is prevented from entering into the building [12].

\section{Heat modulation}

In this strategy, some techniques of heat storage are applied to control the flux of heat [12].

\section{Heat dissipation}

The occurrence of heat dissipation, removing the heat through releasing into a natural reservoir such as air, water and ground, is possible in the following ways [12, 13]:

\section{a. Ventilation}

In natural ventilation, the air movement is carried out based on positive and negative pressure of the wind or through chimney effect in which hot air moves up and cool air moves down and substitute for hot air [3].

\section{b. Evaporative cooling}

The exchange of air heat occurs with the warmth of the water droplets at the wet levels [14].

\section{c. Ground cooling}

The earth has a high thermal capacity which allows for seasonal storage of heat. The greater the depth of the earth, the lower the annual fluctuation of soil temperature, thus,

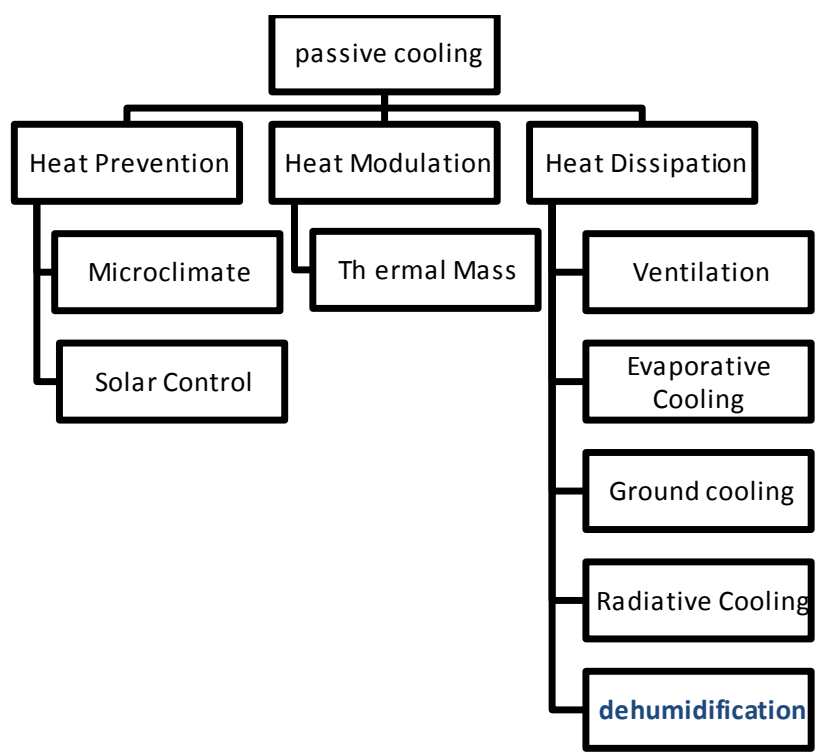

Figure1. Passive cooling strategies in building [12, 13] constant temperature of the earth can be used for the cooling of the building [13]. This type of cooling occurs directly and indirectly. In direct form, part of the building is directly connected to the ground and in indirect form, coolness of the depth is used through buried pipes [15].

\section{d. Radiative cooling}

Radiant cooling is a heat transfer from a warm surface to a cooler surrounding [13].

\section{e. Dehumidification}

Dehumidification is the process of removing vapor from the room air. When the air contains $70-80 \%$ humid, it is used for cooling through three ways of dilution with dry air, distillation and drying $[14,16]$.

\section{SHAVADOONS OF DEZFUL CITY \\ Dezful city}

Dezful city $\left(32^{\circ} 24^{\prime} \mathrm{N}, 48^{\circ} 33^{\prime} \mathrm{E}\right.$ and $140 \mathrm{~m}$ above sea level) is located in Khuzestan province, southwest Iran [17]. The climate of Dezful city is hot and semi-humid [18]. Mean monthly minimum and maximum temperatures during hot months are presented in Table 1.

The climacteric condition of Dezful, especially during the summer, is out of the comfort range, resulting from high temperature. In this regard, two solution should be considered for cooling:

1. Prevention of heat receiving

2. Increasing heat dissipation through air conditioning and appropriate air flow [19].

\section{Shavadoon}

Shavadoon is an innovative architectural design for reaching two above goals. Definition and description of shavadoon and its role in achieving thermal comfort in the climacteric conditions of Dezful city will be discussed further.

TABLE 1. Long-term monthly climacteric data of Dezful city during 2000-2017

\begin{tabular}{lccc}
\hline month & $\begin{array}{c}\text { Precipitation } \\
(\mathbf{m m})\end{array}$ & $\begin{array}{c}\text { Minimum } \\
\text { temperature } \\
\left({ }^{\circ} \mathbf{C}\right)\end{array}$ & $\begin{array}{c}\text { Maximum } \\
\text { temperature } \\
\left({ }^{\circ} \mathbf{C}\right)\end{array}$ \\
\hline January & 70.62 & 0.89 & 19.65 \\
February & 31.47 & 2.0 & 22.48 \\
March & 22.13 & 4.7 & 27.71 \\
April & 29.58 & 10.37 & 35.43 \\
May & 13.67 & 1771 & 41.35 \\
June & 0.0 & 22.54 & 45.2 \\
July & 0.0 & 24.5 & 46.4 \\
August & 0.02 & 24.3 & 45.69 \\
September & 0.58 & 17.45 & 42.55 \\
October & 9.78 & 12.73 & 40.35 \\
November & 40.78 & 5.75 & 32.23 \\
December & 80.36 & 1.87 & 25.3 \\
\hline May, June, July, August and September are considered as hot months of the \\
year (summer and early autumn).
\end{tabular}


Shavadoon is an underground space in the traditional buildings of Dezful city, responding the cool needs of its habitants. Daily rest in the summer and maintenance of food are two importance functions of shavadoon. Regarding the solidity of the soils of Dezful (Conglomerate) [6], shavadoon forms from a excavating in the depth of more than $10 \mathrm{~m}$ with no wall and ceiling construction [1].

To build a shavadoon, the first stage is digging a channel on the ground which eventually turns into entrance staircase of shavadoon. The channel is still being digested up to a depth where no fall occurs. After that, the required spaces of shavadoon are created inside the rock. Stones produced from drilling are moved to the ground surface by a wheel or wicker basket and used as foundation material and for base course and building facades [7].

Light and ventilation in the shavadoon are supplied through a cavity connecting the shavadoon to the yard or rooms of a building or to the alley [7].

The variation of shavadoon temperature during a year compared with outside temperature is presented in Figure 2, indicating that the shavadoon temperature is in the comfort range and changes in above ground temperature has negligible effect on shavadoon temperature.

\section{Shavadoon components}

Shavadoons have many components including entrance, stairway, foot rest, Sahn, Kat, Tal, Daricheh or Darizeh (Figures 3 to 5) [1].

\section{a. Entrance}

The entrance of shavadoon, with a width of $1.2-1.8 \mathrm{~m}$, is usually located in a corner of the yard and, in some cases, on a terrace next to the yard. Most entries are without a door and have a shelter wall around them [1].

\section{b. Stairway}

The stairway starts from the entrance located in the yard and continued to Sahn [18].The slopes of stairways of shavadoon is often more than that of modern stairways [1].

\section{c. Foot rest}

The foot rest is a landing stair which its level and performance is more than a staircase. In the absence of space is foot rest used by the users of shavadoon [1].

\section{d. Sahn}

Sahn is the main component of the shavadoon with a square plan [18].

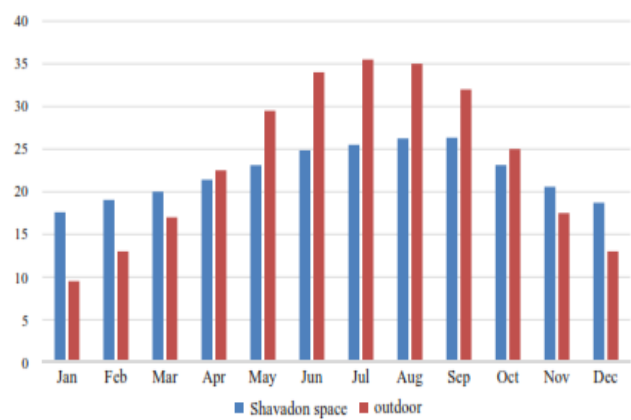

Figure 2. Variation of temperature in the space of shavadoon and living space [5]

\section{e. Kat}

Kat is defined as the spaces which are separated from the Sahn with a level difference. In squared Sahns, the Kat is connected to three sides of Sahn [1].

\section{f. Tal}

The Kats of two neighbor shavadoons are connected to each other through a tunnel or gate named Tal. In fact, Tal is an underground communication network between two family members [1]. During summer days when commuting outside the shavadoon is less than the usual, the connection between the two neighbor shavadoon is provided by a Tal to supply the exchange of the food and other daily needs [18]. Shavadoon is also connected a nearby river or aqueduct through a Tal to benefit the flow of cool air [1].

\section{g. Daricheh or Darizeh}

In the Sahn of shavadoon or Kat, there is an air conditioner which is responsible for air conditioning named Darizeh in Dezful [1]. The diameter of the Darizeh is about $1 \mathrm{~m}$. In addition to vertical air conditioning of shavadoon, Darizeh supply light too. Darizeh is connected to yard, and sometimes alley and the roofs of houses [6].

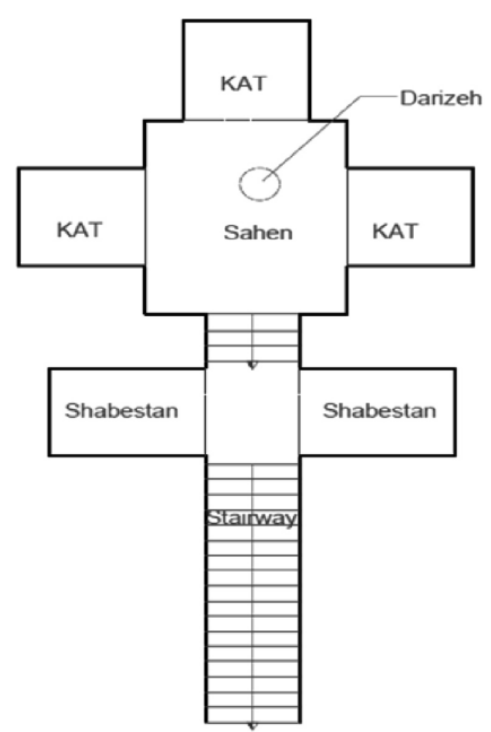

Figure 3. Plan of Shavadoon [10]

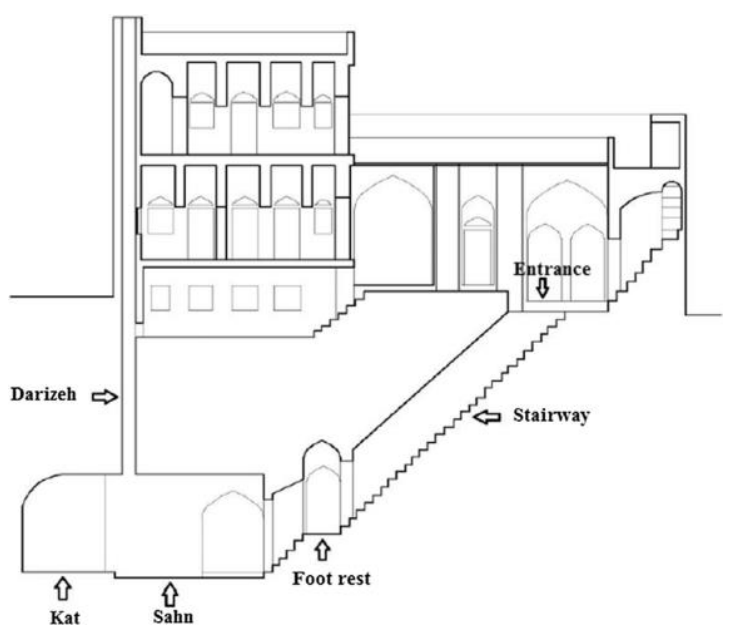

Figure 4. A shavadoon and its components [18] 


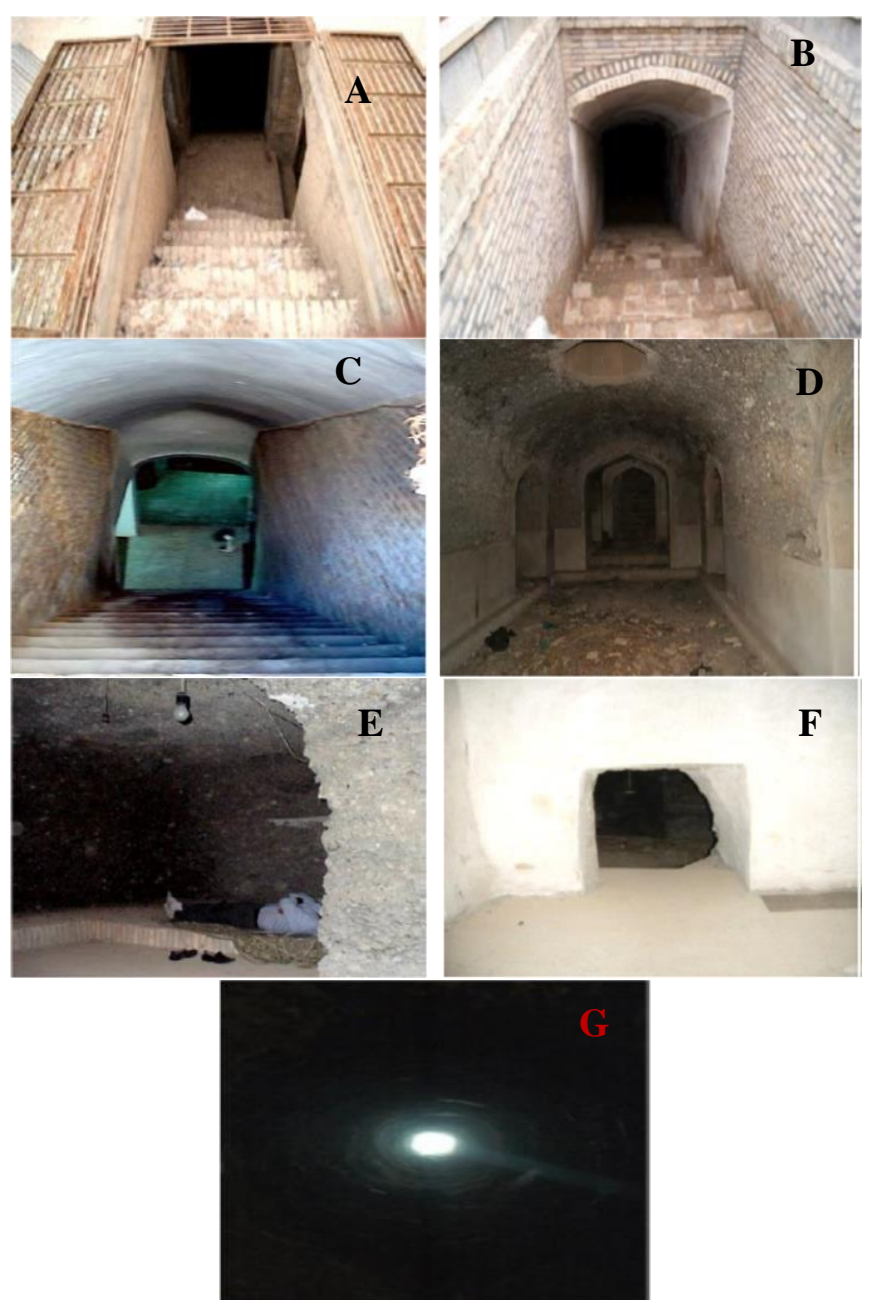

Figure 5. A: The entrance, B: The stairway, C: The foot rest, D: The sahn, E: The kat, F: The Tal, G: The Darizeh of Shavadoon [18]

\section{COOLING IN SHAVADOON RELATED TO THE COMBINATION OF ITS COMPONENTS}

The placement of shavadoon under the ground and other climatic strategies used in it supply cooling needs for its habitants in a static and efficient energy consumption manner. Regarding sha vadoon components, cooling in shavadoon occurs in three ways: ground cooling (direct and indirect), cooling though ventilation (chimney and passing ventilation) and evaporative cooling.

\section{Ground cooling}

Earth surface is heated by receiving the energy of solar radiation. However, the temperature of the lower levels (from the depth of $1 \mathrm{~m}$ ) shows a maximu $\mathrm{m}$ of one degree of change. At a depth of $20 \mathrm{~m}$, there is no variation in temperature. In other word, the temperature is almost constant at depth of $20 \mathrm{~m}$. Seasonal temperature variations affect the temperature of higher depth with a few months delay, resulting in saving winter cool and summer heat for at least for 6 months. In the depth of 5.6m, no variation in air temperature occurs [8]. The annual variation of temperature of different depths of ground in Dezful city is presented in Figure 6.

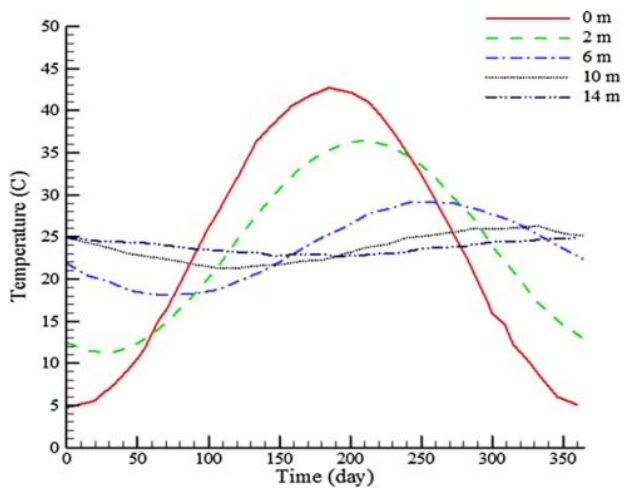

Figure 6. Variation of temperature at different depth of ground during the year [20]

Earth temperature in the depth of Shavadoon has an annual mean of $25^{\circ} \mathrm{C}$. Seasonal variations in air temperature change the temperature of a shavadoon only by $1^{\circ} \mathrm{C}$. The walls have no temperature drop and are permanently cool during the summer. The walls of shavadoon can eliminate the heat produced by the human population and the entry warm air and use it as a energy source without any thermal insulation [1].

\section{Cooling though ventilation}

One of the ways to improve shavadoon temperature is natural ventilation (Figure 7) [6]. In hot cities in southern Iran, it is better to have a two-way air conditioning, where the air enters from one side and goes out from the other site or the roof of the building [4]. Because of hot and semi-humid climate of Dezful, the air of the sky is the only way to access cold air [6]. At night, when the earth does not receive the energy of solar radiation and cool air moves down, at first the roof of the building is cooled by the flow of the cool air (Figure 8). In the next step, cool air flows downward and reaches to lower spaces such as yard and eventually moves toward the lowest point of the building in shavadoon. This cool air stored in shavadoon and habitants use its coolness during the day. Cool air enters shavadoon through its wide entrance, which requires the removal of the hot air. The removal of the hot air is carried out though Darizeh of shavadoon which acts as a chimney. Due to the fact that the hot air flow is upward, there is no natural ventilation during day. Preventing the entrance of hot air to internal space of shavadoon is also essential during day [1].

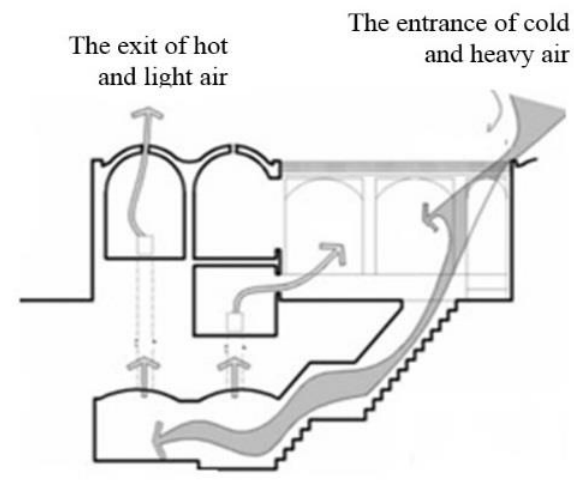

Figure 7. Vertical section of a shavadoon and its ventilation [1] 


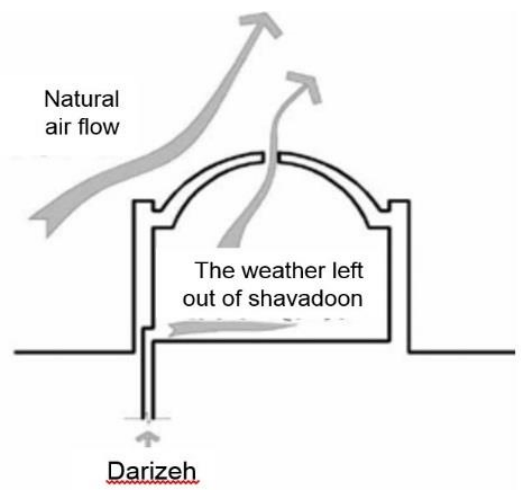

Figure 8. Ventilation at night and removal of heat of building walls [1]

In a research, air flow in Shavadoons of Dezful city was evaluated by a modeling method (cfd, using Design builder ver. 3.0.0.105) and the effect of Shavadoon components design and their interactions on natural ventilation was considered [6]. The results of this experiment revealed that Shavadoon depth, cross section of Darizeh, the place of Darizeh and Shavadoon plan are four factors affecting the natural ventilation of Shavadoon [6]:

While air flow of Azar-abad (Shavadoon with less depth) was lower than that of GHais ari (Shavadoon with more depth) building, Azar-abad Shavadoon had a better natural ventilation and more appropriate performance.

-Regarding the cross section of Darizeh, two types of Darizeh cross section were identified in Dezful city: the first one had a similar entrance and exit cross section size. In the second one, the size of entrance cross section was bigger than that of exit cross section. Modeling analysis showed that indoor air is better derived out when cross sections had a different size in entrance and exit.

modeling analysis revealed that the best place for Darizeh is Sahn and the center of Shavadoon resulting in balanced air ventilation all over the Shavadoon. When Darizeh is placed at Kats, terminal Kats are the superior one, placed opposite the stairs. In this case, air ventilation is optimum in Shavadoon.

There are two types of plans for the Shavadoons of Dezful city: square Chalipa plans. Modelling analysis showed that square plan is a superior plan for better air flow. However, Chalipa is a betterplan regarding structure and architecture of Shavadoon.

\section{Evaporative cooling}

Connecting the shavadoons to each other and the river bank through Tal causes the shavadoons to benefit from the cool air passed through the river or the aqueduct. In places with no access to the river, Tal connects to aqueduct to provide cool air for residents [18].

In Figure 9, the connection of shavadoons to each other and to the river has been shown. The air passed through the

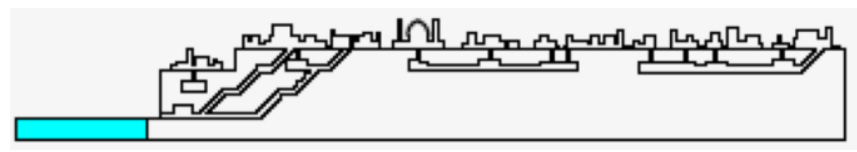

Figure 9. Underground communication between Shavadoons [5] surface of the river and cooled down enters the space of shavadoon through Tal and is effective in creating the conditions for the comfort of the inhabitants.

\section{CONCLUSION}

Nowadays, management of energy consumption and conservation of the environment is one the most important concerns of architects. In traditional architecture of Iran, architects provided comfort for the inhabitants of the building by climatic design and creating precise relationship between buildings and environment. Shavadoon, an underground space, is a climatic design in the architecture of traditional buildings of Dezful city which responds to the air conditioning needs of its inhabitants. Shavadoon has a passive type of cooling which occurs in the three following ways:

1. Ground cooling (direct and indirect)

2. Cooling through ventilation (passing and chimney)

3. Evaporative cooling

Three types of passive cooling, occurring in shavadoon as discussed above.

In this article, studying and benefiting from the experiences of the past in protecting the environment without the need for much energy consuming in the cooling of living spaces has been emphasized which can be a pattern for new energy management methods. Shavadoons of Dezful city are good patterns which can save energy resources through using natural renewable energies.

TABLE 3. Passive cooling in shavadoon component

\begin{tabular}{lc}
\hline $\begin{array}{l}\text { Shavadoon } \\
\text { component }\end{array}$ & passive cooling \\
\hline Sahn and Kat & $\begin{array}{c}\text { - Ground cooling (direct contact) } \\
\text { - cooling through ventilation (passing and } \\
\text { chimney) } \\
\text {-Evaporative cooling }\end{array}$ \\
\hline Tal & - Ground cooling (direct) \\
\hline $\begin{array}{l}\text { Staircase and } \\
\text { Papahn }\end{array}$ & - cooling through ventilation (passing) \\
\hline
\end{tabular}

\section{REFERENCES}

1. Bina, M, 2008. A Climatological Investigation of Shavadoon. Honar- Ha- Ye- Ziba, 33, 37-46 (In Persian).

2. Dehghan, $\mathrm{N}$ and R, Vakili-Nejad, 2016. Investigating the Effective Factors in the Formation of Iranian Underground Architectures. In the proceeding of the 2016 National Conference of Native Architecture \& Urbanism of Iran, 1-11.

3. Ghobadian, V and M. Faiz-Mahdavi, 2008. Climatic Design: Energy- Efficient Building Principles and Practices. University of Tehran Press. 
4. Ghobadian, V, 2008, Climatic Analysis of Traditional Iranian Buildings, University of Tehran Press.

5. Hazbei, M., O. Nematollahi., M. Behnia and Z. Adib, 2015. Reduction of Energy Consumption n Using Passive Architecture in Hot and Humid Climates. Tunneling and Underground Space Technology, 47, 16-27.

6. Hazbei, M., Z. Adib and F. Nasrollahi, 2014. Natural Ventilation Effect on Shavadoons in Dezful by Applying CFD Modeling, Bagh-e-Nazar. Iranian Scientific Journal of NAZAR Research Center for Art, Architecture \& Urbanism, 11(30), 43-54.

7. Khakpour, B., K. Kazemi Khabiri and S.A. Hossainpour, 2013. Investigating the soil and land capabilities of indigenous Iranian sustainable architecture with emphas is on energy management and urban environmental protection. In the proceeding of the 2013 National Sustainable Architecture and Urban Development Conference, 1-6.

8. Madani H and S, Shafiei, 1997. General Geology. Amirkabir University of Technology Press.

9. Masoudi-nejad, M., M. Tahbaz and S.S. Mofidishemirani, 2018. The Study of Thermal Performance of Shavadoons, Case Study: The Sozangar House in Dezful. Iranian Journal of Iranian architecture studies, 1(13), 49-70.

10. Mohammadshahi, Sh., M. Nili-Ahmadabadi and O. Nematollahi, 2016. Improvement of Ventilation and Heat Transfer in Shavadoon via Numerical Simulation: A Traditional HVAC System. Renewable Energy, 96, 295304.

11. Tousi, R, 2015. Evaluation of Static Heating and Cooling Systems in Order to Complete the Basic Concepts of Climatic Integration in a Static Approach to Temperate and Humid Climate of the Caspian Sea. In the proceeding of the 2015 Energy and Environment Conference, 1-8

12. Prieto, A., U. Knaack, T. klein, T. Auer, 2017, 25 Year of cooling research in office buildings: Review for the intergration of cooling strategies into the building façade
(1990-2014), Renewable and Sustainable Energy Reviews, 71, 89-102.

13. Vakilinezhad, R., F. Mehdizadeh Seradj and S.M. MofidiShemirani, 2013. Principles of Passive Cooling Systems in Vernacular Architectural Elements of Iran. Journal of Iranian Association of Architecture \& Urbanism, 4(5), 147-159.

14. Noroozian, N, 2016. Localization Pattern for Assessment of Energy Efficiency in Buildings in Tehran, Naqsh-eJahan. Basic Studies and New Technologies of Architecture and Planning, 6(3), 63-74.

15. Soltandust, M.R. 2012. Climate, Architecture and Ventilation. Yazda Press.

16. Shafiei-Ardestani, L., and S.M. Mofidi-Shemirani, 2009. Geographical Factors and Static Cooling in Residential Complex. Scientific-Research Quarterly of Geographical Data (SEPEHR), 18(71), 38-46.

17. Taban, M., M.R. Pourjafar., M.R. Bemanian and S, Heidari, 2014. Determining Optimal Courtyard Pattern in Dezful Traditional Houses by Relying on Shadow Analysis, Bagh-e Nazar. Iranian Scientific Journal of NAZAR research center (Nrc) for Art, Architecture \& Urbanism, 10(27), 37-46.

18. Samsam-Khayani, H., M. Tavakoli., S. Mohammadshahi and M. Nili-Ahmadabadi, 2018. Numerical Study of Effects of Shavadoon Connections (a Vernacular Architectural Pattern) on Improvement of Natural Ventilation. Tunneling and Underground Space Technology, 82, 170-181.

19. Zamani-Aghaie, L and N. Bareshadat, 2012. Architecture looking at the Land, Shavadoon is an Ancient Heritage in the Southern Architecture. In the proceeding of the 2012 National Conference of Cultural Industries and their Role in Sustainable Development, 1-7.

20. Moradi, H. and H. Eskandari, 2012. An Experimental and Numerical Investigation of Shovadan Heating and Cooling Operation. Renewable Energy, 48, 364-368.

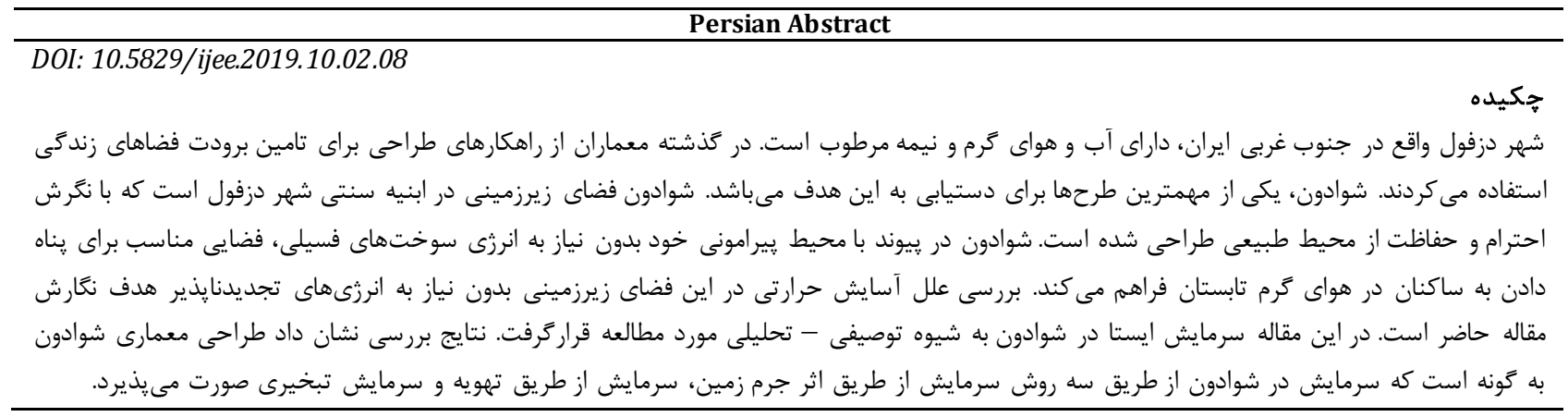

